\title{
Mapping of Soil Erosion Zones of Meghadrigedda Catchment, Visakhapatnam, India for Conservation -A Geospatial Approach
}

\author{
Usha Chirala', Murali Krishna Gurram², Nooka Ratnam Kinthada ${ }^{3}$ \\ ${ }^{1}$ Department of Geo-Engineering, College of Engineering (A), Andhra University, Visakhapatnam, India \\ ${ }^{2}$ GIS Technology \& Applications, GIS Division, Xinthe Technologies Pvt. Ltd., Visakhapatnam, India \\ ${ }^{3}$ Department of Geology, College of Science and Technology, Adikavi Nannaya University, Rajahmundry, \\ India \\ Email: u chirala@yahoo.com, murali.krishna.gurram@gmail.com, ratna k12@yahoo.com
}

Received 14 January 2015; accepted 2 April 2015; published 7 April 2015

Copyright (C) 2015 by authors and Scientific Research Publishing Inc.

This work is licensed under the Creative Commons Attribution International License (CC BY). http://creativecommons.org/licenses/by/4.0/

(c) (i) Open Access

\begin{abstract}
Meghadrigedda, a non-perennial drainage system is one of the major water resources of Vishakhapatnam city located in the northern coastal region of Andhra Pradesh, India. It traverses through the hilly terrain of Eastern GhatMobile Belt (EGMB) characterized by khondalitic rock formations. Excessive siltation scenario aggravated due to soil erosion in its catchment is threatening the very existence of Meghadrigedda reservoir. In order to assess the intensity of soil erosion as well as silt deposition in the reservoir, an integrated study has been undertaken which takes into consideration various topographic, morphological, soil, and land use/land cover characteristics of the basin. The study aims at identification and mapping of erosion prone zones with respect to silt deposition using remote sensing and GIS techniques. Alteration in human induced land use practices in its catchment due to rapid growth in population, urbanization and industrialization are found to be of prime reasons for various forms of erosion. The study has noticed that various forms of erosion like sheet, gully and stream erosion are responsible for the siltation at large scale which is causing reduction of its designed storage capacity by $40 \%$. Various sub-watersheds of the basin have been prioritized on the basis of erosion intensity for suggesting various mitigation measures like check-dam construction, afforestation etc. to protect the reservoir from the silting problem.
\end{abstract}

\section{Keywords}

Meghadrigedda, GIS and Remote Sensing, Erosion, Siltation of the Reservoir, 


\section{Soil Conservation}

\section{Introduction}

Soil erosion is a major environmental problem which threatens the sustainability and productivity of agricultural and other hydrological systems [1]. Therefore, proper assessment and mapping of soil erosion is very essential for the management of natural resources [2]. Every year, about 75 billion tons of soil is eroded from the land due to human induced land use practices, a rate that is about 13 - 40 times faster than the natural rate of erosion. Over exploitation of land and water resource for various means of developmental activities by rapidly growing population has been inflicting severe damage to soil environment. According to the study conducted by [3], about 148.9 Mha area representing $45.3 \%$ of the Total Geographical Area (TGA) of the country is affected by various forms of soil degradation caused by water, wind, chemical and other physical agencies. Soil erosion is considered as one of the major problems that the Indian agriculture sector is coping with and its negative effects are seen in other spheres as well. It is noticed that, every year India losses millions of tons of soil and its nutrients to the agents of its degradation which adversely affects our national productivity.

A reservoir built across the River Meghadrigedda has a very high value in terms of feeding the major drinking water needs of Visakhapatnam city and agricultural needs in the catchment. Population in the catchment is mostly dependent on agriculture, livestock, and forestry for livelihood. Environmentally, the catchment area has been under tremendous pressure due to increasing population, industrialization and over exploitation of natural vegetation for timber and fuel wood. The catchment has been witnessing rapid urbanization and undergoing large scale topographic transformation which is leading to vegetation loss and soil erosion resulting in silt deposition in the reservoir. The storage capacity of the reservoir is rapidly dwindling due to the excessive siltation and the problem is posing a major risk to the very existence of the reservoir.

\section{Study Area}

Meghadrigedda is one of the prominent river catchments originated in the hilly terrain of Visakhapatnam and Vizianagaram districts of Andhra Pradesh. The river joins the Bay of the Bengal in the south near Visakhapatnam Figure 1. A medium scale reservoir was constructed across the river with a gross capacity of $1163 \mathrm{~m} \cdot \mathrm{ft}^{3}$ in the year 1972 near Kamparapalem village, Visakhapatnam. The river catchment is extended in an area of $368 \mathrm{~km}^{2}$ which includes the reservoir area. Geographically, the catchment extends within the northern latitudes of $17^{\circ} 42^{\prime \prime}$ to $17^{\circ} 57^{\prime \prime}$ and eastern longitudes of $83^{\circ} 0^{\prime \prime}$ to $83^{\circ} 17^{\prime \prime}$.

The entire catchment is extended within nine administrative sub-district units (also called mandals) of Visakhapatnam and Vizianagaram districts of the state of Andhra Pradesh. Around $94 \mathrm{~km}^{2}$ of upper catchment area lies within the Kottavalsa sub-district which comes under the jurisdiction of Vizianagaram district and the rest of the sub-districts comeunder the Visakhapatnam district Table 1. Majorpart of the study area is covered with forests of which considerable extent of the area falls under the reserved forest category, covered by Potukonda, Narava, Nallkonda, Ellappi, Yerrakonda and Dabala reserved forests. The catchment is covered with nearly 521 minor non-perennial/perennial tanks which do not however significantly reduce the flood peaks and their duration. The catchment receives the maximum amount of rainfall during southwest and northeast monsoon seasons which starts from June to December. The river reaches its peak levels mostly during the months of October and November due to the influence of cyclonic storms in the Bay of Bengal. The area enjoys sub-tropical climate and temperatures range from $14^{\circ} \mathrm{C}-20^{\circ} \mathrm{C}$ in December and $33^{\circ} \mathrm{C}-42^{\circ} \mathrm{C}$ in May. The temperature goes down with the onset of southwest monsoon and tumbles to a mean minimum of $21^{\circ} \mathrm{C}$ by January after which there will bea reversal trend till the temperature reaches mean maximum of $32.7^{\circ} \mathrm{C}$ by the end of June. The district receives an annual rainfall of $1202 \mathrm{~mm}$. As per the 2011 census [4], the provisional population of the district is 42.88 lakhs with a growth rate of $11.89 \%$, which constitutes $5.06 \%$ of the population of the state while the geographical area of the district is $11,161 \mathrm{~km}^{2}$ which is only $4.1 \%$ of the area of the state.

\section{Materials and Methods Used for the Study}

Topographical maps of 1:50,000 scale published by Survey of India (SOI) numbered 65 O/1, 65 O/2\&3 and 65 

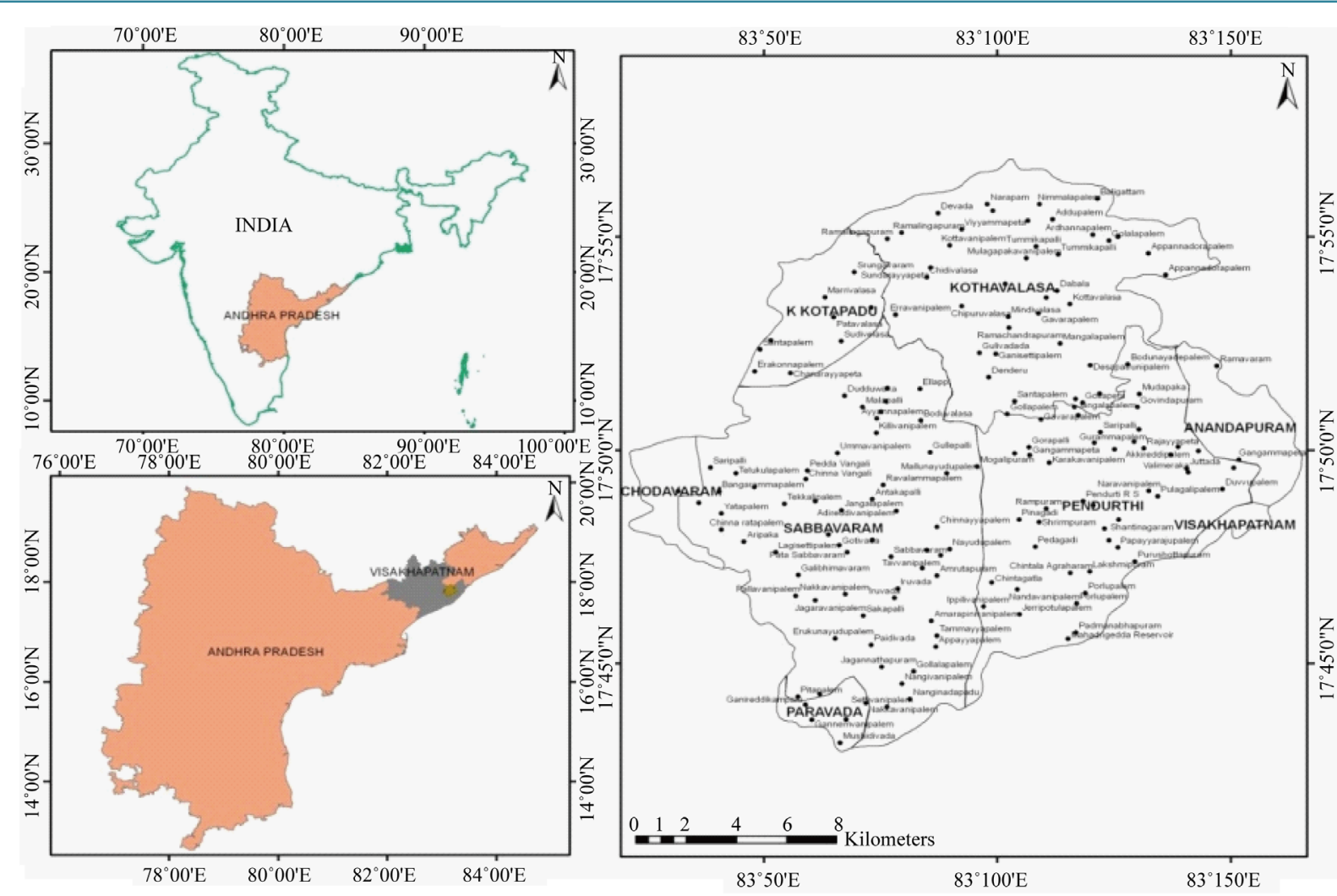

Figure 1. Location map.

Table 1. Area covered by the sub-districts (mandals) in the study area.

\begin{tabular}{ccc}
\hline S. No & Mandal name & Area in $\mathbf{~ k m}^{\mathbf{2}}$ \\
\hline 1 & Anakapalli & 0.25 \\
2 & Anandapuram & 16.42 \\
3 & Chodavaram & 9.42 \\
4 & K. Kotapadu & 21.97 \\
5 & Kottavalsa & 93.32 \\
6 & Paravada & 5.80 \\
7 & Pendurthi & 83.67 \\
8 & Sabbavaram & 134.33 \\
9 & Visakhapatnam & 2.82 \\
& Total & $\mathbf{3 6 8}$ \\
\hline
\end{tabular}

O/5 have been georeferenced and the mosaic was used as the base map for the study. Multi-temporal Remote sensing data obtained using IRS-IB LISS III of 1997, IRS-ID LISS III of 1999, IRS-ID LISS III of 2006 and IRS-ID LISS III of 2009 were used for the study. The LISS III sensor data has the spatial resolution of $23.5 \times 23.5$ $\mathrm{m}$ with 7-bit radiometric resolution. The data has been georeferenced by taking the georeferenced topographic mosaic as a reference.

Various map themes as inputs required for the integration have been prepared by means of interpreting the data through manual digitization. Authenticity of the feature data extracted for all the map themes were rechecked and 
verified through field checks. The field checks were conducted by collecting samples from nearly 63 villages and 71 hamlets located in the study area and necessary corrections were incorporated.

Drainage and contour layers were extracted from the topographic maps and were used to generate the drainage density and Digital Elevation Model (DEM). The drainage density map is prepared by drawing all the drainage patterns from the topographical map. A grid of $1 \mathrm{~km} \times 1 \mathrm{~km}$ is drawn on the entire base map. The cumulative stream lengths are computed in each grid, and the drainage density in each grid is calculated using formula $\mathrm{Lu} / \mathrm{A}$.

DEM generated using contours was used to create the slope map for the study area. The slope map gives various groups/categories of slope as defined in the technical guidelines for integrated study.

The land use/land cover theme reveals the present status of natural and anthropogenic activity which transforms the characteristics of the terrain. The land use/land cover theme for the study area has been delineated from the IRS-ID LISS III data of February, 2009 using the four level classification scheme defined by the National Remote Sensing Center [NRSC] [5]. The analysis was carried out by employing the visual interpretation techniques and the data has been verified with the ground truth data.

The soil map for the study area has been generated using the district soil maps published by National Bureau of Soil Survey and Land Use Planning (NBSS \& LUP) by taking the georeferenced remote sensing data as a reference.

\section{Weighted Analysis of the Sub-Basins}

In order to perform the spatial analysis to identify and map the zones of high erosion intensity, all the mapped data inputs had to be reclassified according to their soil erosivity characteristics. These reclassified themes are overlaid in the GIS environment to arrive at soil prioritization zones for the entire area which has been divided into nine sub-basins. Various thematic layers such as slope, drainage density, land use/land cover, geomorphology and soil have been used to arrive at soil priority zones. Union of all these layers has been used to generate a theme which will be used to further delineate the areas of soil erosion. The areas which are prone to soil erosion in the study area have been delineated and classified according to the method defined by the National Water Development Program for Rainfed Areas (NWDPRA).

\subsection{Drainage Density $\left(D_{d}\right)$}

According to the classification proposed by [6], all the drainage sub-basins of Meghadrigedda have been reclassified into three different zones, such as, poor, medium and excellent based on their $D_{d}$ values Figure 2. Subsequently, weightfactors have been assigned to all the sub-basin categories. The weight factors have been assigned in a way that the sub-basins with $D_{d}$ value more than $1.5 \mathrm{~km} / \mathrm{km}^{2}$ (coded as A) would get the weightage factor of 1 . Similarly, sub-basins with $D_{d}$ between $0.5-1.5 \mathrm{~km} / \mathrm{km}^{2}$ (coded as B) have been given the weightage factor of 2 and sub-basins with $D_{d}$ less than $0.5 \mathrm{~km} / \mathrm{km}^{2}$ (coded as C) are assigned with the weightage factor of 3 , respectively Table 2. The reclassification of the sub-basins is done in a way that $D_{d}$ values indirectly reflects the intensity of soil erosion, it means, higher the $\mathrm{D}_{\mathrm{d}}$, higher the soil erosion and vice-versa.

\subsection{Slope}

Slope is considered as one of the critical parameter for identifying the erosion intensity zones of the study area. The slope theme originally with seven different categories has been reclassified into three categories indicating the intensity of erosion based on the given weight criteria Figure 3. The first category of reclassified slope theme is formed by including the previous three slope categories, such as, 5, 6 and 7, (coded as D) by assigning a weightage factor of 1 , and considered as the high erosion category. The $2^{\text {nd }}$ reclassified category of slope, which re-

Table 2. Codes and weight factors assigned to different zones of drainage density.

\begin{tabular}{cccc}
\hline Drainage density & Polygon code & Weight & Class \\
$>1.5 \mathrm{~km}$ & $\mathrm{~A}$ & 1 & High erosion \\
$0.5-1.5 \mathrm{~km}$ & $\mathrm{~B}$ & 3 & Medium erosion \\
$<0.5 \mathrm{~km}$ & $\mathrm{C}$ & Low erosion & \\
\hline
\end{tabular}




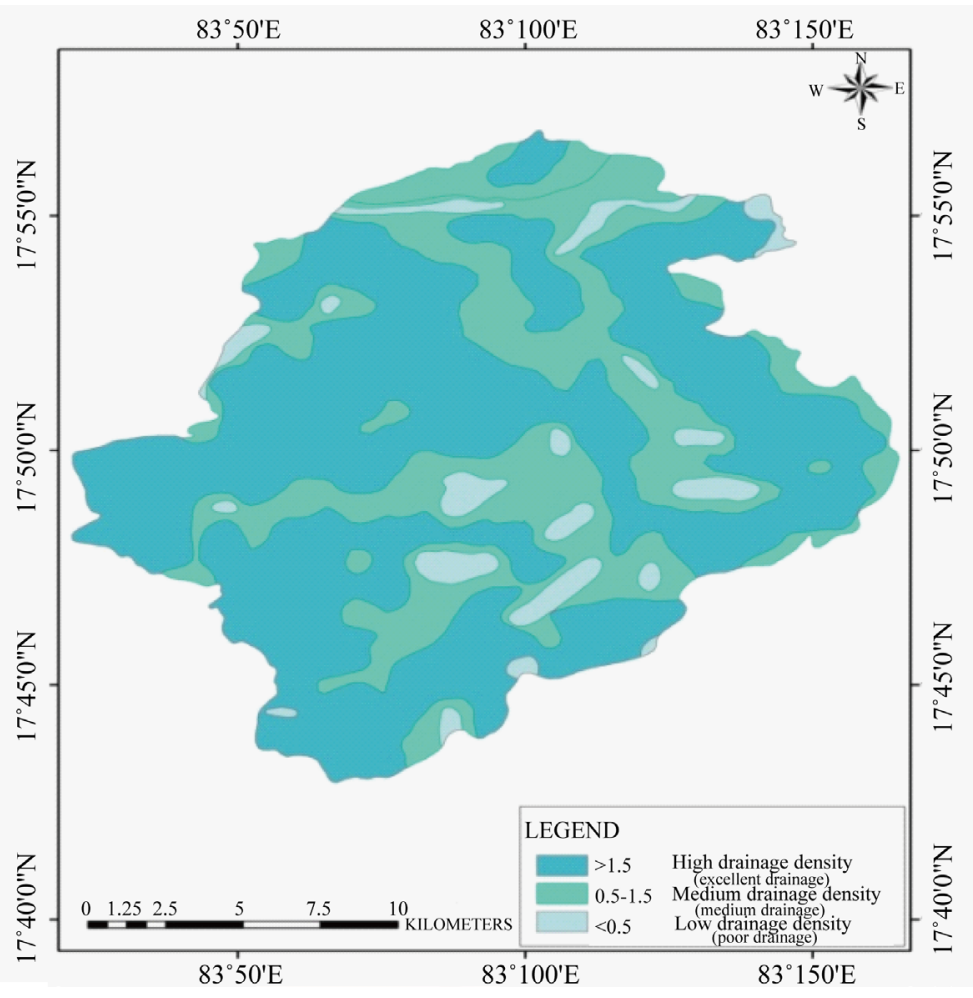

Figure 2. Drainage density map of the study area.

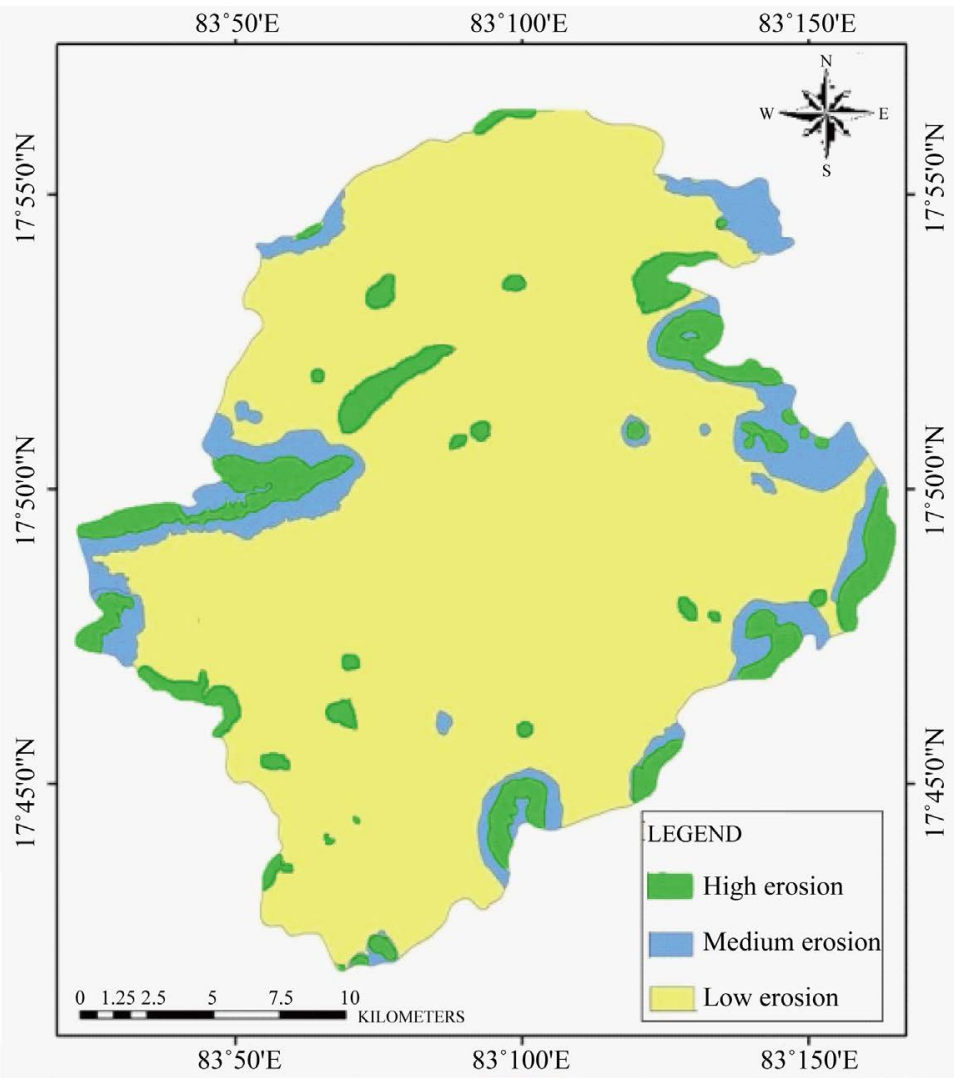

Figure 3. Slope categories of the study area. 
presents zones with medium erosion intensity were formed by reclassifying of the previous $3^{\text {rd }}$ and $4^{\text {th }}$ categories of the slope (coded as E) and assigned a weightage of 2. Finally, the third category of reclassified slope was formed by grouping of $1^{\text {st }}$ and $2^{\text {nd }}$ category of previous slopes (coded as F) and given a weightage factor of 3 , which represents the areas with low erosion intensity. The basis for the weightage criteria is decrease in the value of slope, i.e., areas with low slope gradient represents the zones of no/or less erosion and vice-versa. Table 3 shows regions with slope limits, assigned polygon code, their weightage factors and the erosion class.

\subsection{Land Use/Land Cover}

Land use/land cover is acclaimed as one of the important surface character which plays a vital role in determining the intensity of erosion. Land use/land cover mapping of the Meghadrigedda resulted in various land use/land cover categories, of which cultivation is noticed as the major land use class, followed with plantation, deciduous forest, etc. Of all the land use/land cover categories mapped in the study area, only those categories which have a direct bearing on soil erosion are taken into consideration for delineating erosion prone zones. As such, four different reclassified units of land use/land cover categories with respective codes, weight factors and classes indicating the intensity of soil erosion taken into consideration for the analysis. The first category coded as " $G$ " has been formed by reclassifying of various land use/land cover classes, such as, gullied ravinous, badland, upland with dense scrub, upland with sparse scrub etc., and assigned with a weightage factor of 1 which represents high intensity of erosion. The $2^{\text {nd }}$ category coded as " $\mathrm{H}$ " is formed with reclassifying of land use/land cover classes, includes plantation and un-irrigated land and assigned with a weight of 2, which represents areas of medium to high erosion intensity. The $3^{\text {rd }}$ category coded as "I" formed with the class "forest" alone by assigning a weight of 3 representing areas with medium erosion intensity. Finally, the $4^{\text {th }}$ category coded as " $\mathrm{J}$ " was formed with classes, such as, tanks, reservoir and irrigated areas with a weight factor of 4 and represents the low erosion intensity areas Figure 4.

\subsection{Soil}

Soil is another vital parameter without which the study of erosion analysis has to be considered incomplete. Soil forms the upper most layer and composed of unconsolidated earth material which is susceptible to erosion. Besides its natural conditions, soil erosion is triggered by anthropogenic activities. The soils of the Meghadrigedda catchment have been reclassified into four categories and each of them has been given a code with weight factors ranging between 1 to 4 according to the intensity of erosion Table 4 and Figure 5 . The shallow skeletal soils in the catchment have been coded as "K" with a weight factor of 1 representing the areas of high erosion. Gravelly loams are coded as " " with a weight factor of 2 representing the areas of medium to high erosion. Similarly, red loams and clays are coded with "M" with a weight factor of 3 representing medium erosion. Finally, clayey soils are coded with "N" with weight factor of 4 representing low intensity of erosion Table 5.

\subsection{Generation of Map Composites}

A composite map is a combination of two or more base maps depicting some or all features from the base maps. A composite map has been generated by overlaying two different map themes on each other. The resultant composite is the union of both the map themes and inherits the characteristics from both. For instance, a polygon denoted as " $\mathrm{A}$ " in the drainage map with a weightage factor " 1 " when combines with a polygon of the slope map denoted as "E" with a weightage factor "2", assumes a new polygon code as "AE" on the composite map with its area being the lesser of the two and with a weightage factor equalizing the sum of the weights of both "A" and "E", i.e., " 3 ".

Table 3. Codes and weight factors assigned to different slope categories.

\begin{tabular}{cccc}
\hline Slope category & Polygon code & Weight & Erosion class \\
\hline $5,6,7$ & $\mathrm{D}$ & 1 & High erosion \\
3,4 & $\mathrm{E}$ & 2 & Medium erosion \\
1,2 & $\mathrm{~F}$ & 3 & Low erosion \\
\hline
\end{tabular}




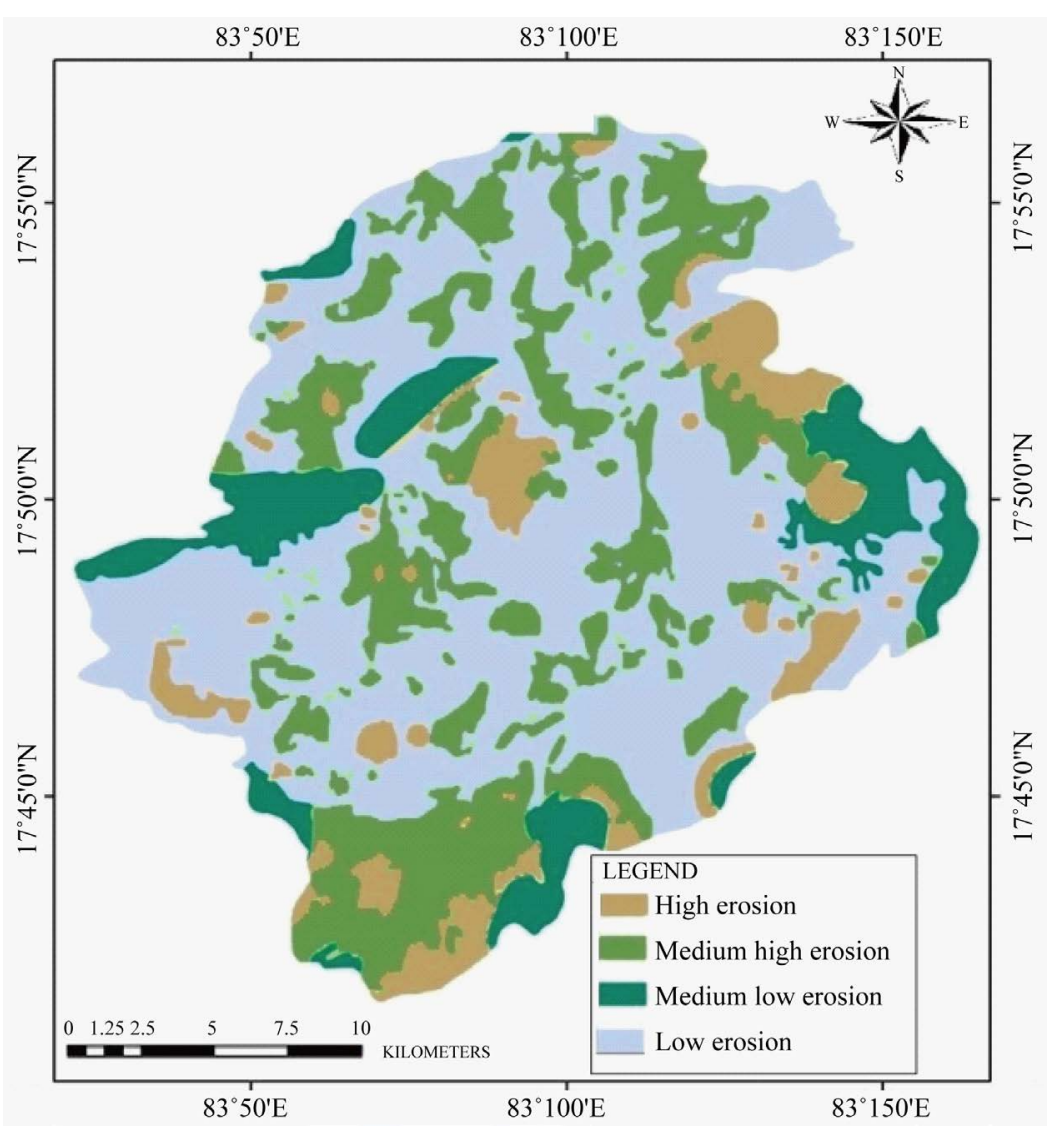

Figure 4. Land use/land cover categories reclassified according to the erosion intensity.

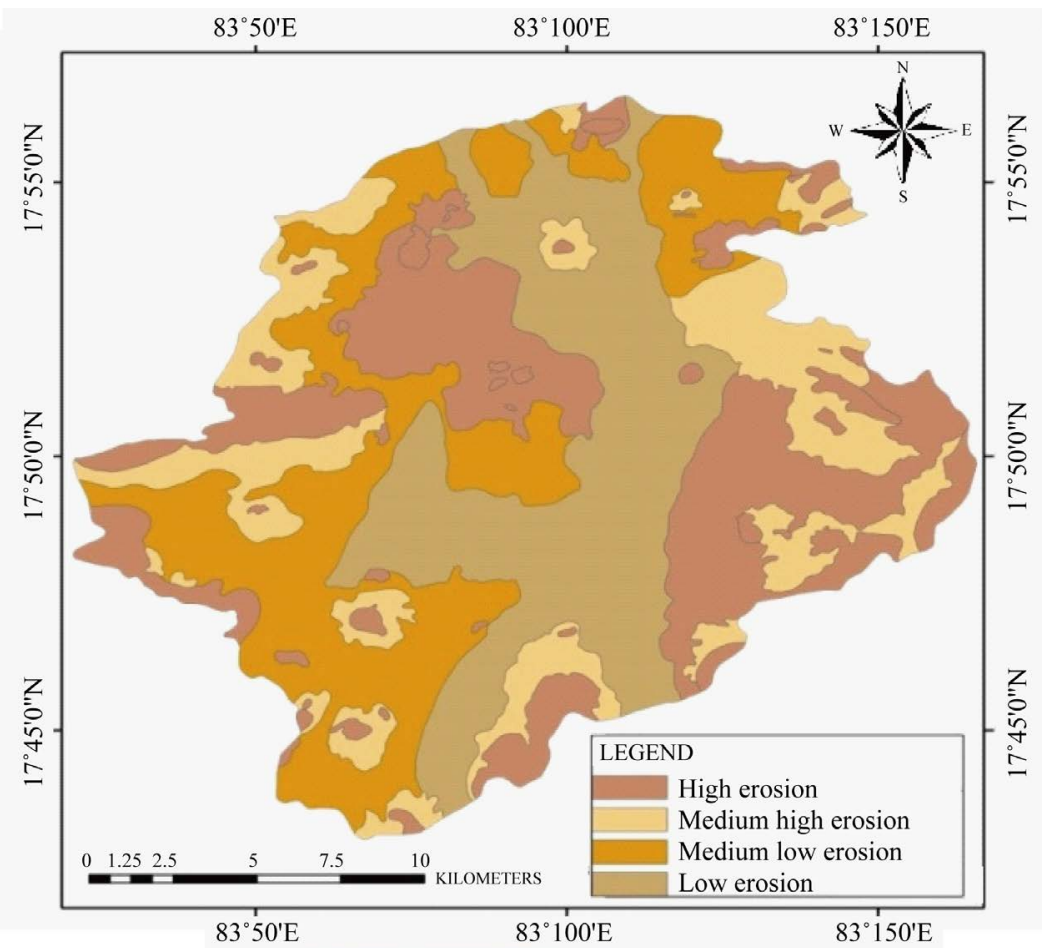

Figure 5. Soil map of the study area reclassified according to the erosion intensity. 
Table 4. Codes and weight factors assigned to different soil categories.

\begin{tabular}{cccc}
\hline Soil category & Polygon code & Weight factor & Erosion class \\
\hline Shallow skeletal soils & $\mathrm{K}$ & 1 & High \\
Gravelly loams & $\mathrm{L}$ & 2 & Medium high \\
Red loams and clays & $\mathrm{M}$ & 3 & Medium \\
Clayey soils & $\mathrm{N}$ & 4 & Low \\
\hline
\end{tabular}

Table 5. Weights assigned to the zones of composite 1 for classification according to erosion intensity.

\begin{tabular}{cc}
\hline Combined classes & Weight factors \\
\hline AD & 2 \\
AE & 3 \\
AF & 4 \\
BD & 3 \\
BE & 4 \\
BF & 5 \\
CD & 4 \\
CE & 5 \\
CF & 6 \\
\hline
\end{tabular}

\subsubsection{Map Composite 1}

The first composite map was prepared by the integration of slope and drainage density maps. All the resultant (overlapping) feature class combinations such as, AD, AE, AF, BD, BE, BF, CD, CE and CF were delineated. Each combined class was assigned with a weightage factor according to the degree of susceptibility to erosion. The zones which have been identified along with their cumulative weight factors for further analysis as shown in Table 5. Subsequently, the zones which have been categorized into low, medium and high erosion classes are mapped accordingly Figure 6.

\subsubsection{Map Composite 2}

The second map composite was generated by the integration of the land use/land cover theme with the soil. The resultant map has the combination of different feature classes from land use/land cover and soil themes. The map has resulted in the feature combinations, such as, GK, GL, GM, GN, HK, HL, HM, HN, IK, IL, IM, IN, JK, JL, JM and JN. All the classes have been assigned with certain weights as shown in Table 6 for further analysis. These classes have been categorized, such as low, low to medium, medium to high and high based on their susceptibility to erosion Figure 7.

\section{Discussion: Integration for Prioritization}

Both the reclassified composite themes have been used for the preparation of final erosion map which will be used for the classification of the zones for final prioritization. Weight factors have been assigned to each overlapping feature class after the integration. These weightage factors helps reclassification of eleven resultant classes indicating different degrees of soil erosion intensity into seven prioritized classes and further down to four classes ranging from "very severe" to "low" erosion areas which are prone to different degrees of erosion Figure 6 and Figure 7. The final areas along with the weight factors used for prioritization with respect to their erosion class, level and areal extent in $\mathrm{km}^{2}$ are presented in Table 7 . These seven classes have been prioritized according to the intensity of erosion Table 8 and have been assigned the priorities for conservation Table 9. These zones have been further reclassified into four classes of erosion intensity, namely, very severe, severe, moderate and low. This is done by denoting the very high priority areas as "severe" since they are prone to high intensity of erosion and 


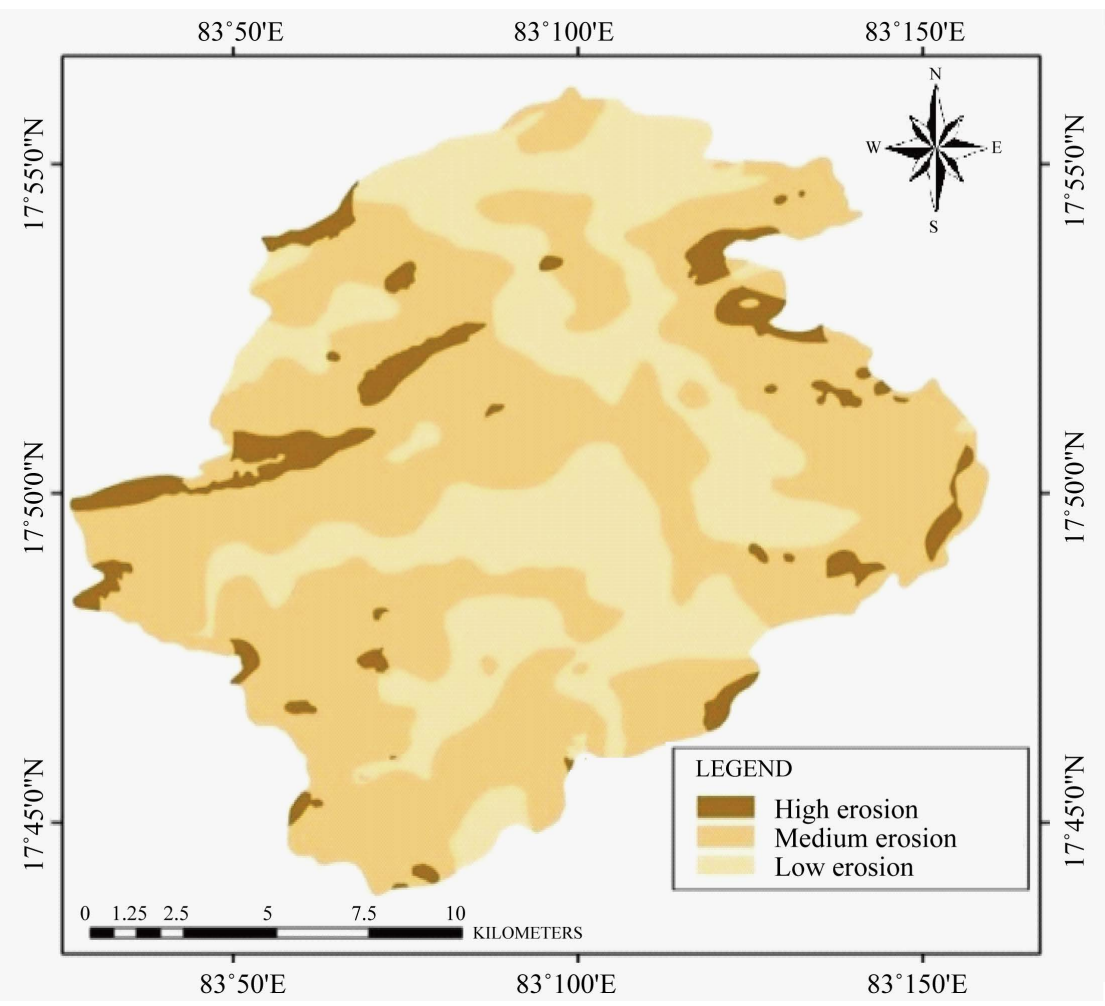

Figure 6. Composite 1 generated by integrating "slope” and "drainage density” classified according to the suceptability to erosion.

Table 6. Weights assigned to the zones of composite 2 for classification according to erosion intensity.

\begin{tabular}{cc}
\hline Combined classes & Weight factors \\
\hline GK & 2 \\
GL & 3 \\
GM & 4 \\
GN & 5 \\
HK & 3 \\
HL & 4 \\
HM & 5 \\
HN & 6 \\
IK & 4 \\
IL & 5 \\
IM & 6 \\
IN & 7 \\
JK & 7 \\
JL & 5 \\
JM & 6 \\
JN & 7 \\
& 8 \\
\hline
\end{tabular}




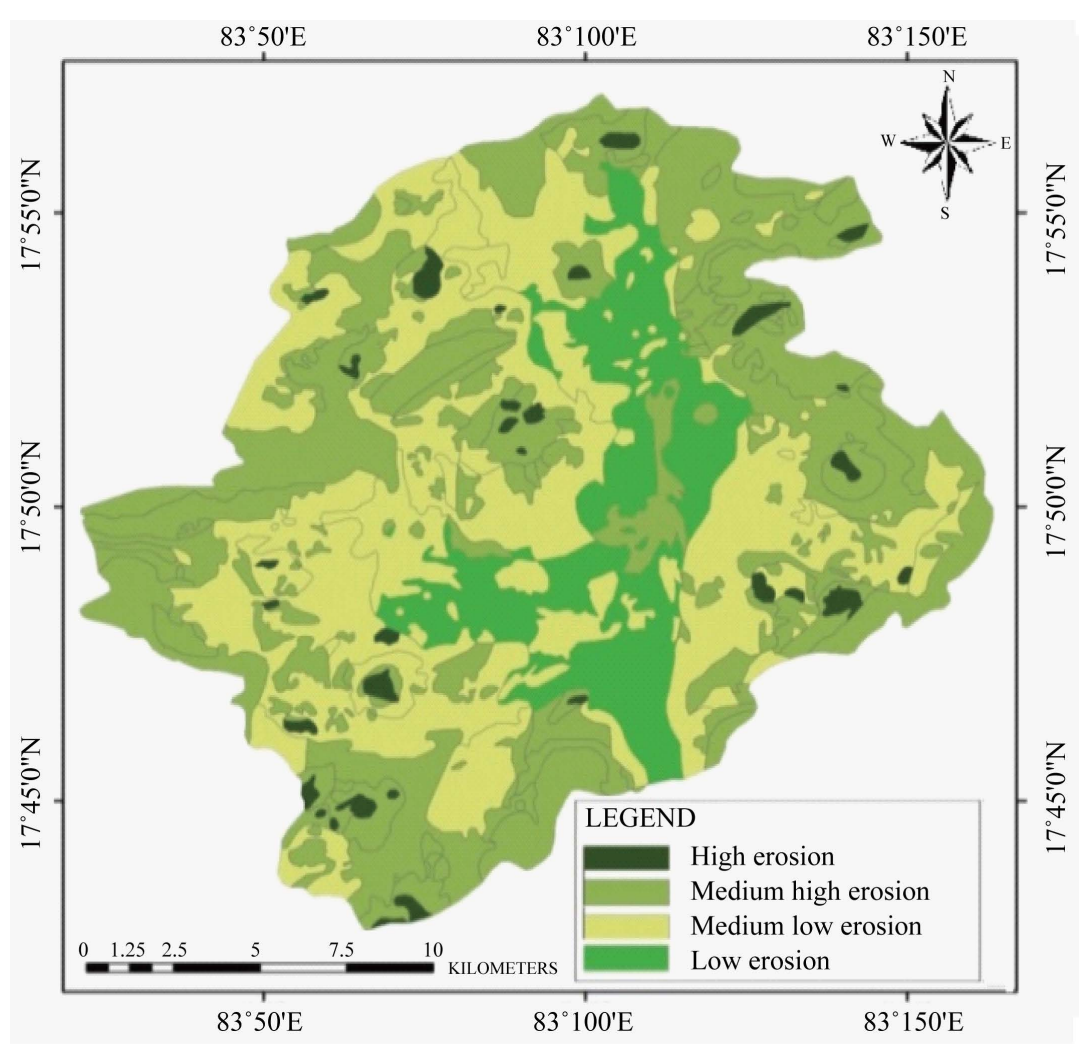

Figure 7. Composite 1 generated by integrating "soil” and "land use/land cover" classified according to the suceptability to erosion.

Table 7. Weight factors assigned to the integrated zones of the study area.

\begin{tabular}{cc}
\hline Combined classes & Weight factors \\
\hline GK & 2 \\
GL, HK & 3 \\
GM, HL & 4 \\
GN, HM, IL, JK & 5 \\
HN, IM, JL & 6 \\
IN, JM & 7 \\
JN & 8 \\
\hline
\end{tabular}

Table 8. Different erosional classes indicating the severity of erosion in the study area.

\begin{tabular}{ccccc}
\hline S. No & Soil erosion class & Erosion class & Area in $\mathbf{k m}^{\mathbf{2}}$ & Severity of erosion \\
\hline 1 & 4 & E4 & 5.46 & Very severe erosion \\
2 & 5 & E4 & 7.97 & Very severe erosion \\
3 & 6 & E3 & 27.25 & Severe erosion \\
4 & 7 & E3 & 32.4 & Severe erosion \\
5 & 8 & E3 & 22.06 & Severe erosion \\
6 & 9 & E2 & 40.71 & Moderate erosion \\
7 & 10 & E2 & 33.53 & Moderate erosion \\
\hline
\end{tabular}


needs immediate soil conservation measures. Similarly, the zones which have been given the "least" priority are categorized as "low" erosion intensity zones Table 10.

Various conservations measures are recommended in the Meghadrigedda catchment for arresting the erosion especially in the areas identified with high erosion intensity. The conservation measures have also taken into consideration of the prevailing local conditions. A brief descriptive summary of different sub-basins in the Meghadrigedda with their physiography characteristics and erosion intensity is given in Table 11 . The zones that are

Table 9. Reclassified soil erosion zones in the study area.

\begin{tabular}{|c|c|c|c|}
\hline S. No & Priority class & Area in $\mathbf{k m}^{2}$ & Percentage of area \\
\hline 1 & Very high & 16.58 & 4.50 \\
\hline 2 & Medium high & 6.08 & 1.65 \\
\hline 3 & High & 35.90 & 9.75 \\
\hline 4 & High Medium & 38.15 & 10.36 \\
\hline 5 & Medium & 45.93 & 12.48 \\
\hline 6 & Low Medium & 186.56 & 50.69 \\
\hline 7 & Low & 38.80 & 10.54 \\
\hline \multicolumn{2}{|c|}{ Total } & 368 & 100.00 \\
\hline
\end{tabular}

Table 10. Prioritized erosional zones along with their areal distribution.

\begin{tabular}{cccc}
\hline Order of priority & Priority class & Area in $\mathbf{~ k m}^{\mathbf{2}}$ & Percent area \\
\hline 1 & Very severe erosion & 16.58 & 4.5 \\
2 & Severe erosion & 80.13 & 21.77 \\
3 & Moderate erosion & 232.49 & 63.17 \\
4 & Slight erosion & 38.80 & 10.56 \\
Total & $\mathbf{3 6 8}$ & $\mathbf{1 0 0}$ & \\
\hline
\end{tabular}

Table 11. Sub-basins of Meghadrigedda with description of their physiography, erosion intensity and priority for conservation.

\begin{tabular}{|c|c|c|}
\hline Sub-basin & $\begin{array}{l}\text { Priority for } \\
\text { conservation }\end{array}$ & Description of the sub-basin, physiography and erosion intensity \\
\hline 1 & 1 & $\begin{array}{l}\text { Isolated hillocks are composed of quartzite and migmatite type of rocks as intrusive in khondalite country } \\
\text { ricks. Dendritic parallel drainage patterns are prominently seen in khondalite hillocks and plains. It has } \\
\text { moderate slopes with more perennial tanks. }\end{array}$ \\
\hline 2 & 2 & $\begin{array}{l}\text { The rock type observed is khondalite. Highly denuded rocks, sub-dendritic drainage pattern rolling } \\
\text { topography with moderate slopes. At place sparse and discontinuous drainage is observed down below next to } \\
\text { the reservoir area with khondalite rock presence. }\end{array}$ \\
\hline 3 & 7 & $\begin{array}{l}\text { Dendritic drainage developed over drainage country rock with low slopes. Perennial tanks with moderate } \\
\text { storage capacity observed. }\end{array}$ \\
\hline 4 & 8 & $\begin{array}{l}\text { Radial, dendritic and sub-dendritic drainage patterns are observed. Khondalite rock with rolling topography is } \\
\text { observed. }\end{array}$ \\
\hline 5 & 9 & $\begin{array}{l}\text { Sparse and discontinuous drainage is observed. The discontinuous drainage is due to anthropogenic activity in } \\
\text { this watershed. It is located in the reservoir area with natural khondalite rock abutment. }\end{array}$ \\
\hline 6 & 4 & $\begin{array}{l}\text { This is a part of Naravagedda drainage basin which is the main tributary to Meghadrigedda river. The rock } \\
\text { types are khondalite and quartzite. Steep slopes are confined in the hilly terrain. Higher rate of denudation and } \\
\text { rolling topography are the characteristic features of this sub-basin. }\end{array}$ \\
\hline 7 & 5 & $\begin{array}{l}\text { This sub-basin is the major drainage of the Naravagedda river. Landmass denudation, steep slope with rill } \\
\text { erosion and khondalite and migamatite types of rocks are exposed. }\end{array}$ \\
\hline 8 & 3 & $\begin{array}{l}\text { This basin is located in the upper catchment of the river, where the tock types are khondalite and migamatite. } \\
\text { The migamatite occurs as intrusive in khondalite massif. Moderate slope with varied type of drainage pattern } \\
\text { are common in this sub-basin. }\end{array}$ \\
\hline 9 & 6 & $\begin{array}{l}\text { This sub-basin is the origin of the river Meghadrigedda. Different types of drainage patterns with moderate } \\
\text { slope, feather like drainage basin features are observed. Khondalite rock type prevails. }\end{array}$ \\
\hline
\end{tabular}




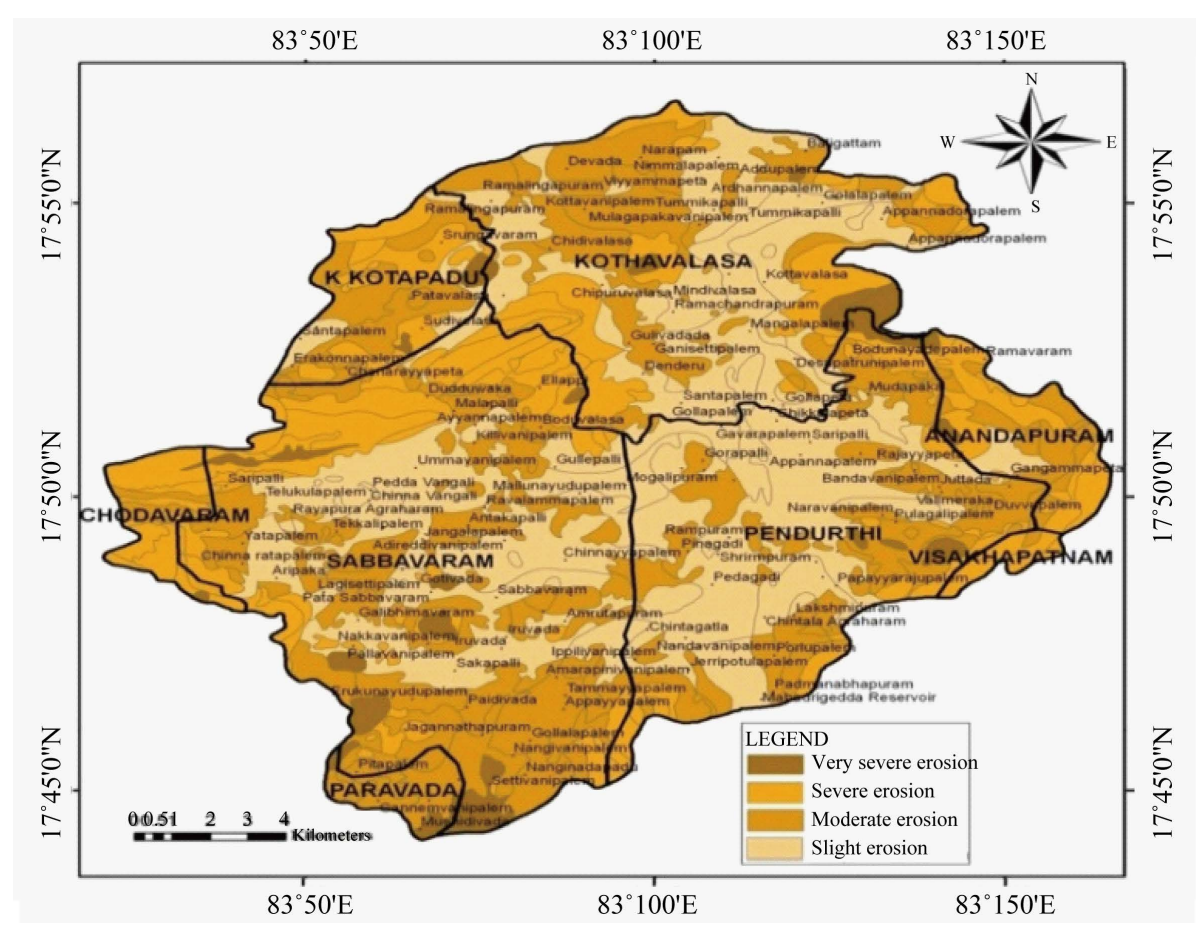

Figure 8. The sub-basins of Meghadrigedda mapped according to the intensity of erosion.

identified with very severe erosion covering in an area of $16.58 \mathrm{~km}^{2}$ i.e., $4.5 \%$ i.e. $4.8 \%$ of the total area is recommended for social forestry and for growing the fruit bearing trees to conserve the soil. The sub-basins of Meghadrigedda with different erosion intensity zones are shown in Figure 8. The other zones of erosion were recommended with soil conservation measures such as, silt traps, contour bunding and check dams taking into account of the erosional and topographical conditions of the area.

\section{Conclusion}

Siltation is identified as the major problem in Meghadrigedda reservoir which is gradually reducing its holding capacity year after year and also affecting the water supply system connected to it. The possibility of desiltation of the reservoir by means of dredging is totally ruled out due to various practicality reasons, such as, magnitude of the reservoir, difficulty in handling the process and the cost factor. Various soil conservation measures in the catchment are thought out as the best alternative solution. The measures include social forestry for the high erosion intensity areas. The remaining areas in the catchment are recommended with measures such as, checking dam construction, silting traps, contouring bunding etc. with respect to the prevailing topographical conditions. It is believed that the above recommended measures can be very effective in arresting the burgeoning siltation problem in the Meghadrigedda reservoir.

\section{Acknowledgements}

The authors would like to thank the Dept. of GIS, INRIMT, Hyderabad, India for its support in mapping.

\section{References}

[1] Quinton, J.N., Govers, G., Van Oost, K. and Bardgett, R.D. (2010) The Impact of Agricultural Erosion on Biogeochemical Cycling. Nature Geo Science, 3, 311-314. http://dx.doi.org/10.1038/ngeo838

[2] Baskan, O., Cebel, H., Akgul, S. and Erpul, G. (2010) Conditional Simulation of USLE/RUSLE Soil Erodiblity Factor by Geostatistics in a Mediterranean Catchment, Turkey. Environmental Earth Science, 60, 1179-1187. http://dx.doi.org/10.1007/s12665-009-0259-2

[3] Sehgal, J. and Abrol, I.P. (1994) Soil Degradation in India: Status and Impact. Oxford and IBH Publishing Co., New Delhi, 80 . 
[4] Handbook of Statistics (2011) Chief Planning Officer, Visakhapatnam District, 226.

[5] National Remote Sensing Agency (2004) Manual on National Land Use/Land Cover Mapping on 1:250,000 Scale Using Multi-Temporal IRS P6-AWiFS Data. NRSA, Dept. of Space, Govt. of India, Balanagar. http://bhuvan-noeda.nrsc.gov.in/theme/thematic/tools/document/LULC250/1011.pdf

[6] Deju, A.R. (1971) Regional Hydrology Fundamentals. Gordon \& Breach Publishing Group, 204. 